\title{
Smoke induced flow in two rooms mechanically ventilated and linked with a horizontal vent type opening
}

\author{
HUGUES PRETREL ${ }^{1}$, KEVIN VARRALL ${ }^{1}$, LAURENT AUDOUIN ${ }^{1}$, OLIVIER VAUQUELIN ${ }^{2}$ \\ (1) Institut de Radioprotection et de Sûreté Nucléaire (IRSN), \\ PSN-RES, SA2I, Laboratoire Commun ETIC, \\ Centre de Cadarache, Bâtiment 346, 13115 St Paul Lez Durance, France, \\ (2) Aix-Marseille Université (AMU), \\ IUSTI UMR 6595, Laboratoire Commun ETIC, \\ 5 rue Enrico Fermi, 13453 Marseille France
}

\begin{abstract}
This work deals with smoke movements between two mechanically ventilated compartments interconnected by a vent. Based on large scale fire tests, it discusses the effect of vent flow on smoke stratification. The tests concern a $97 \mathrm{~kW}$ propane fire in a $120 \mathrm{~m}^{3}$ enclosure connected to an adjacent $170 \mathrm{~m}^{3}$ enclosure, both mechanically ventilated. The renewal rate is the varying parameter (from $2.3 \mathrm{~h}^{-1}$ to $8 \mathrm{~h}^{-1}$ ) typical to operating conditions in nuclear installations. The present contribution investigates the effect of the vent flow on the smoke distribution in both rooms. The temperature and species concentration distributions are analyzed. The effect of ventilation flow rate on the smoke filling and the smoke distribution in both rooms is presented. From mass balance equations, an indirect method is proposed to compute the flow rates at vent (net, upward and downward) only from gas temperatures and species concentrations in both rooms without considering direct measurements at the vent. This indirect method is compared to a direct method (computation of flow rates from spatial integration of temperature and velocity field at the vent cross section). The analysis discusses the application of this indirect method for large scale fire test experiments
\end{abstract}

KEYWORDS: smoke, compartment fire, fluid dynamic, industrial fire

\section{NOMENCLATURE LISTING}

\begin{tabular}{llll}
$\dot{\mathrm{m}}$ & Mass flow rate $(\mathrm{kg} / \mathrm{s})$ & Greek & \\
$M$ & Molar mass $(\mathrm{g} / \mathrm{mol})$ & $\rho$ & Density $\left(\mathrm{kg} / \mathrm{m}^{3}\right)$ \\
$h i$ & Interface height $(\mathrm{m})$ & \multicolumn{2}{c}{ Subscripts } \\
$H R R$ & Heat release rate $(\mathrm{W})$ & $\mathrm{O}_{2}$ & Oxygen \\
$P$ & Pressure $(\mathrm{Pa})$ & $\mathrm{CO}_{2}$ & Carbon dioxide \\
$Q v$ & Volumetric flow rate $\left(\mathrm{m}^{3} / \mathrm{s}\right)$ & $F$ or $F R$ & Fire room \\
$R$ & Perfect gas constant & A or AR & Adjacent room \\
$t$ & Time $(\mathrm{s})$ & $v$ & Ventilation or vent \\
$T r$ & Renewal rate $\left(\mathrm{h}^{-1}\right)$ & in & Ventilation inlet \\
$T$ & Temperature $\left({ }^{\circ} \mathrm{C}\right)$ & out & Ventilation exhaust \\
$V$ & Volume $\left(\mathrm{m}^{3}\right)$ & net & net \\
$X$ & Volume fraction $(\mathrm{mol} / \mathrm{mol}$ or $\% \mathrm{vol})$ & up & Upward or upper layer \\
$Y$ & Mass fraction $(\mathrm{g} / \mathrm{g})$ & down & Downward \\
$z$ & Vertical coordinate & &
\end{tabular}

\section{INTRODUCTION}

Smoke movement is a key issue for safety assessments in nuclear installations. Smoke is responsible for the propagation of heat and soot particles that can impair safety systems such as Equipment Important for Safety (EIS). Typical events to be prevented are the clogging of high efficiency filters (HEPA) located in the ventilation network or the failure of electrical or electronic devices. Particular smoke flows are those observed through open areas such as doorways, vents or reduced orifices used for running cables, for instance. These transfer flows, mainly governed by mixed convection (buoyancy and inertia), are often multidirectional (at least bidirectional), turbulent and have variable densities. When the opening is directly connected to the fire enclosure, the vent flow may have a significant influence on the combustion regime by modifying the fluxes of oxygen entering into the enclosure or the fluxes of combustion products 
exhausted toward adjacent rooms. Understanding and predicting (from zone code or CFD approaches) such flows are major issues for the safety assessments of nuclear facilities.

The present contribution focuses on the vent flow and its effect on the smoke flow in the enclosures connected to the vent (Figure 1 (a)). The flow regime at the vent can be unidirectional upward, bidirectional or unidirectional downward. The differences of temperature and pressure at the vent are criteria that defined the flow regime. In natural convection, the flow is bidirectional with equal mass flow rates in both directions. When a pressure difference is applied to the vent due to the effect of mechanical ventilation for instance, mixed convection flow is encountered. There is a positive and negative critical pressure difference (flooding pressure) above which the counter-flow opposed to buoyancy is nil and only unidirectional flow remains. Basic experimental studies have established the theoretical basis of such vertical flow (Brown [1], Epstein [2], Heskestad [3] and Tan \& Jaluria [4]). From these approaches and the corresponding data base, Cooper [5] [6] proposes a correlative approach for the prediction of vent flow. However, there are very few studies focusing on this type of smoke flow and the Cooper models, which are used in most fire zone codes, have been validated on limited number of experiments. In addition, the correlation has been developed using a dataset obtained from reduced-scale experiments. The validation of fire codes based on large scale fire tests is limited [7], [8], especially for confined and mechanically ventilated enclosures. For such situations, there is still a real need for experimental and theoretical investigations, in order to validate the models and to improve the thorough understanding of these flows.
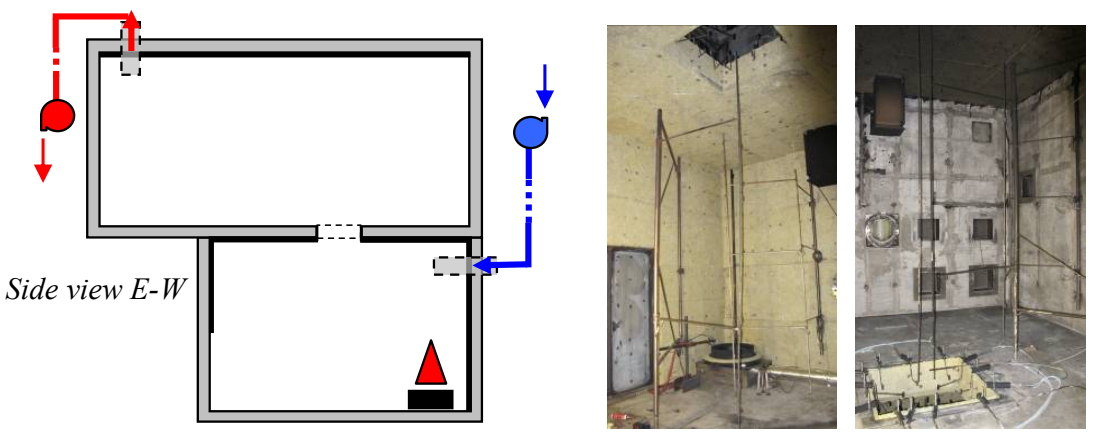

Fig. 1. Schematic illustration of the facility.

Over the past decade, the French "Institut de Radioprotection et de Sûreté Nucléaire" (IRSN) and the "AixMarseille Université" (AMU) has developed research expertise in the effects of mechanical ventilation on smoke flow in confined enclosures in the frame of the common laboratory ETIC. The present contribution concerns the behaviour of the vent flow in the specific configuration presented in Fig. 1 with two closed and mechanically-ventilated rooms. A fire is located in the lower room and a horizontal vent connects the two rooms. The ventilation configuration is particular with one admission line in the fire room and one exhaust line in the upper adjacent room. With such a configuration, the positive effect of the pressure difference with buoyancy can be investigated. Vent flow is affected by three dynamic phenomena: buoyancy due to the heat release from the fire, inertia due to the mechanical ventilation and local momentum from the local smoke flow, such as from a ceiling jet for instance. Pretrel \& al. [9] presented these fire scenarios focusing on the experimental determination of the vent flow and the comparison with Cooper correlation. The present contribution goes further in the investigation of the effect of the vent flow on the smoke distribution in both rooms. The temperature and species concentration distributions are analyzed. The effect of the ventilation flow rate on the smoke filling and the smoke distribution in both rooms is discussed. From mass balance equations, an indirect method is proposed to compute the flow rates at vent (net, upward and downward) only from gas temperatures and species concentrations in both rooms without considering direct measurements at the vent. This indirect method is compared to a direct method which consists in computed flow rates directly from spatial integration of temperature and velocity field at the vent cross section (Pretrel \& al. [9]). The analysis discusses the application of the indirect method, developed for small scale experiments, for large scale fire test experiments. 


\section{FIRE TEST}

\section{Configuration}

The scenario consists of two superposed rooms that are separated by a vent (Fig. 1). The room dimensions are $\left(4 \mathrm{~m}\right.$ in height $\left.\times 5 \mathrm{~m} \times 6 \mathrm{~m}=120 \mathrm{~m}^{3}\right)$ for the lower room and $\left(4 \mathrm{~m}\right.$ in height $\left.\times 5 \mathrm{~m} \times 8.5 \mathrm{~m}=170 \mathrm{~m}^{3}\right)$ for the upper room. The walls are made in re-enforced concrete, of which some areas are covered with $30 \mathrm{~mm}$ rock-wool panels in order to maintain internal wall temperature within safety limits. The wall areas are the ceiling of both rooms and the upper parts (about $2 \mathrm{~m}$ ) of the side walls in the fire room. The fire source is a propane gas fire located in one corner (North-West) of the lower room.

The ventilation configuration consists of one admission line in the lower room and one exhaust line in the upper room. Both branches (inlet and exhaust) are situated in the upper part of the rooms $(0.80 \mathrm{~m}$ from the ceiling). The ventilation set-up is connected to a large industrial ventilation network equipped with blowing and exhaust ventilation fans.

The vent is a rectangular orifice with the dimensions $1030 \mathrm{~mm} \times 1030 \mathrm{~mm}=1.061 \mathrm{~m}^{2}$, located at the centre of the fire room (off-centre in the upper room). The overall depth of the orifice is $385 \mathrm{~mm}$, which corresponds to the $300 \mathrm{~mm}$ thickness of the concrete wall separating the two rooms and a layer of rock wool.

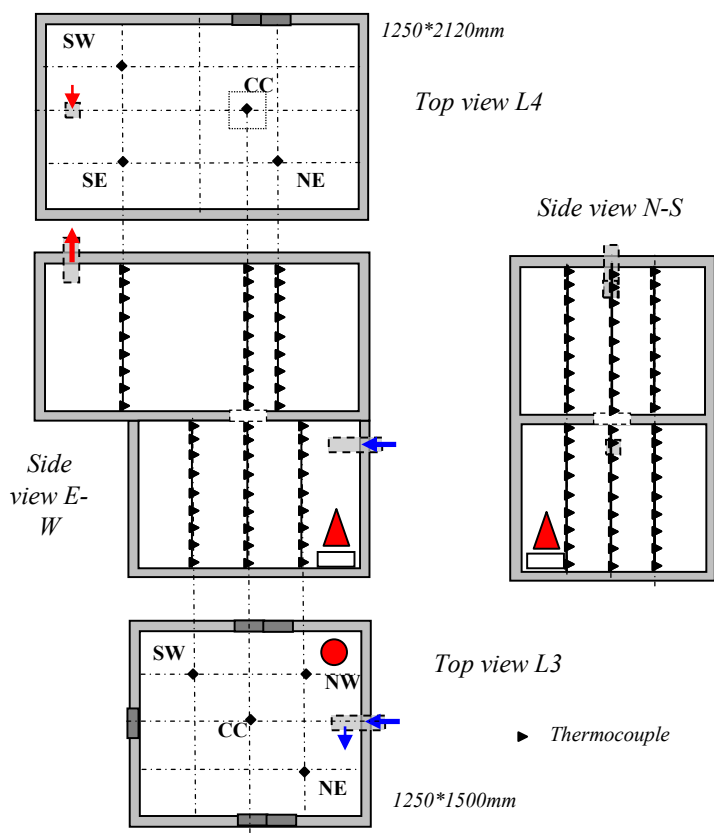

(a)
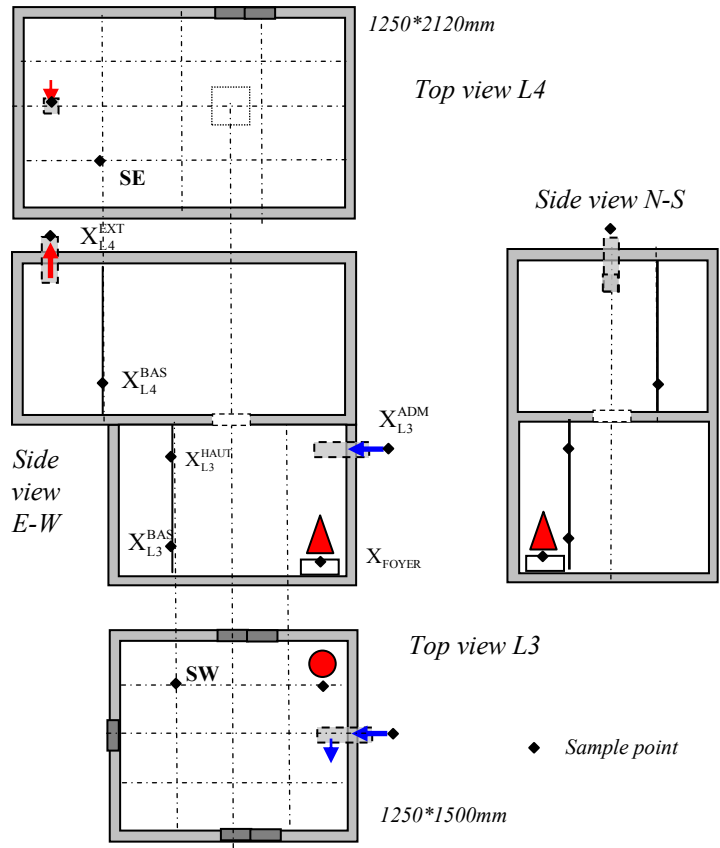

(b)

Fig. 2: Location of the thermocouples and pictures of the rooms.

\section{Measurements}

The two rooms comprise four thermocouples trees named SW, CC, NE and SE for the upper room L4, and SW, CC, NW and NE for the fire room L3 (cf. Fig. 3-a). Each mast is equipped with 9 K-type thermocouples located at $0.05 \mathrm{~m}, 0.55 \mathrm{~m}, 1.05 \mathrm{~m}, 1.55 \mathrm{~m}, 2.05 \mathrm{~m}, 2.55 \mathrm{~m}, 3.05 \mathrm{~m}, 3.55 \mathrm{~m}$ and $3.90 \mathrm{~m}$, from the ground.

The fire room is equipped with two sample points named $X_{L 3}{ }^{B A S}, X_{L 3}{ }^{H A U T}$ in the lower (BAS) and upper (HAUT) part of the room. The adjacent room is only equipped with one sample points named $X_{L 3}{ }^{B A S}$ in the lower part of the room. Two sample points are located in the ventilation network $X_{L 3}{ }^{A D M}, X_{L 4}{ }^{E X T}$ in the admission and exhaust lines of the ventilation network. The sample points in the rooms are fixed to the thermocouple trees located in the South-East corner for room L4 and in the South West corner for room L3. 
They are situated at about $950 \mathrm{~mm}$ from the ground for the sample point "BAS" and $3100 \mathrm{~mm}$ from the ground for the sample point "HAUT" (Fig. 3).

Each sample point is connected to sampling system and gas analyzers for oxygen and carbon dioxide. Molar fraction are measured with SERVOMEX( XANTRA 4100 or EMERSONC Xstream for oxygen and SIEMENS@ ULTRAMAT $22-23$ or EMERSONC Xstream for carbon dioxide. The sampling system controls pressure and flow rate and dries the gas sample. The molar fractions, presented here, are based on dry sample. The sampling system leads to time delay that is corrected after making cross-correlation processing with the nearest thermocouple signal.

\section{Fire source, test matrix and experimental procedure}

A set of four large scale fire tests are considered. The fire heat release rate is fixed at $97 \mathrm{~kW}$ and the renewal rate, $T r$, is the varying parameter (see Table 1). The renewal rate is computed as the ratio between the admission volumetric flow rate before fire ignition and the total volume of the two rooms, $\operatorname{Tr}=q_{v} / V$ $\left(V=120+170=290 \mathrm{~m}^{3}\right)$. The fire heat release rate $(H R R)$ is obtained from the propane volumetric flow rate measurement multiplied by the gas density $\left(\rho_{C 3 H 8}=1.81 \mathrm{~kg} / \mathrm{m}^{3}\right)$ and the effective combustion enthalpy for propane $(\Delta H c=46 \mathrm{MJ} / \mathrm{kg})$. The low value of the HRR has been chosen in order to limit the effect of local momentum due to the ceiling jet near the vent flow.

The experimental procedure is as follows: First the ventilation network is put into place in order to achieve the targeted ventilation flow rate. Then the gas burner is turned on. A mixed convection flow begins to occur at the vent, and smoke progressively fills the adjacent room. The fire HRR is constant over the test duration. The test is stopped (gas burner turned off) once the situation is identified as having reached a steady state. This determination is based on the velocity and gas temperature at the vent and the vertical temperature stratification within the two rooms.

Table 1: Test matrix.

\begin{tabular}{|c|cccc|}
\hline Test & Q17 & Q13 & Q16 & Q12 \\
\hline \hline HRR $(\mathrm{kW})$ & 97 & 97 & 97 & 97 \\
$\left.\mathrm{TR}^{-1} \mathrm{~h}^{-1}\right)$ & 2.3 & 4 & 6.2 & 8 \\
$\mathrm{Qv}\left(\mathrm{m}^{3} / \mathrm{h}\right)$ & 621 & 1080 & 1674 & 2160 \\
\hline
\end{tabular}

\section{TYPICAL BEHAVIOUR}

\section{Gas temperature}

The time variation of the gas temperature in both rooms show a rapid increase at the beginning of the fire test followed by a slow and progressive increase with a rate less than $1{ }^{\circ} \mathrm{C} / \mathrm{min}$ (Fig. 3). A complete steady regime is never obtained. This phase is considered as quasi steady regime. The behavior is very similar between the two rooms.

Vertical temperature profiles are defined during the steady period and presented in Fig. 4. In the fire room, the temperature is maximum in the upper part of the room and minimum in the lower part. Similar behavior is observed in the adjacent room except above the vent (tree CC_L4). That location corresponds to the vertical axis of the smoke plume characterized with a decrease of temperature with height. A comparison of the shape of the temperature profiles between the fire room and the adjacent room shows different behaviors. In the fire room, the vertical profile shows significant change in temperature with two large gradients near the boundaries (ground, $z=[0 ; 1 \mathrm{~m}]$ and ceiling $z=[0 ; 4 \mathrm{~m}]$ ). In the adjacent room, there is only a significant vertical gradient near the ground $(z=[0 ; 1 \mathrm{~m}])$. Above this region, the temperature increases smoothly with height. 
Q13 test, $97 \mathrm{~kW}, \mathrm{~T}(\mathrm{t})$, Fire room, $\mathrm{SW}$ axis

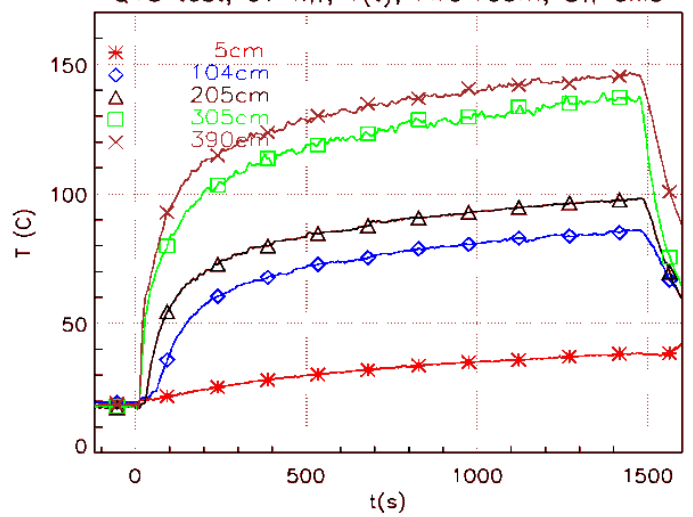

Q13 test, $97 \mathrm{~kW}, \mathrm{~T}(\mathrm{t})$, Adjocent room, SW axis

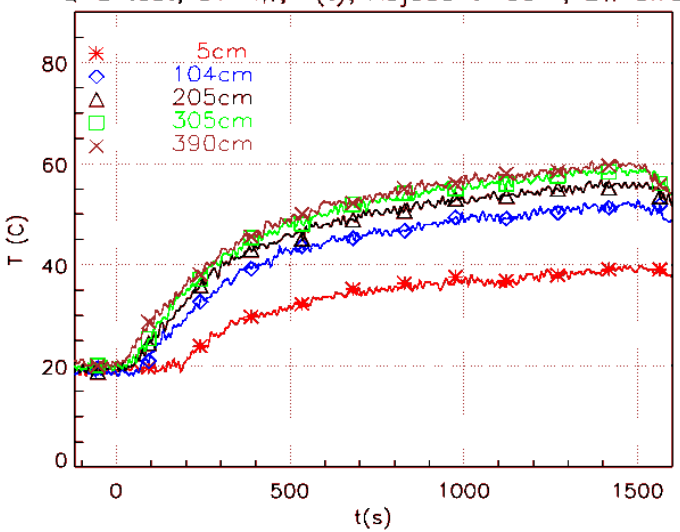

Fig. 3. Example of time variation of the gas temperature in both fire and adjacent rooms (axis SW in both rooms).

Regression methods are used to extract from the temperature profiles an upper and lower layer's temperatures $\left(T_{U}\right.$ and $\left.T_{L}\right)$ and a position of an interface height $h_{i}$. Several methods are available in the literature and the one considered in this study takes into account constant gradient in the upper layer (Audouin \& al [10]). An example of result is presented in Fig. 5 for test Q13. The experimental profile on which the regression method is applied, is a mean vertical profile computed from the three local profiles (trees SW, CC and NE in the fire room and trees SW, SE and NE in the adjacent room). In the steady period, the smoke layer fills all the room and the interface is localized near the floor in both rooms. The theoretical profile indicated in Fig. 5 shows the constant gradient within the upper layer. There is no lower layer and the upper layer fills all volume of the rooms.

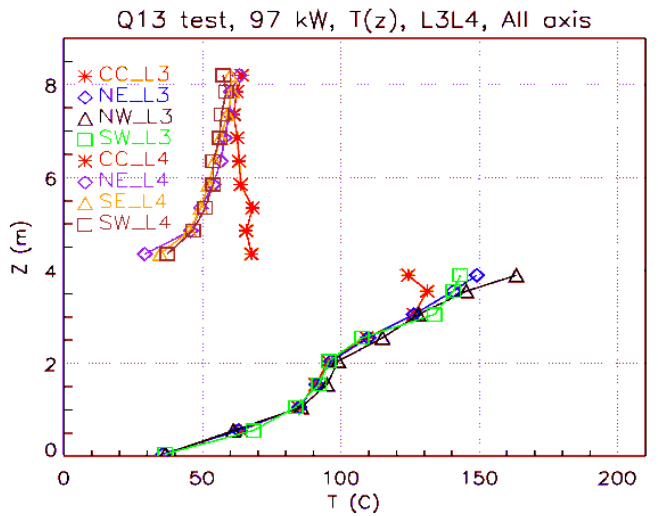

Fig. 4. Example of vertical temperature profiles in the fire and adjacent rooms during the steady phase.

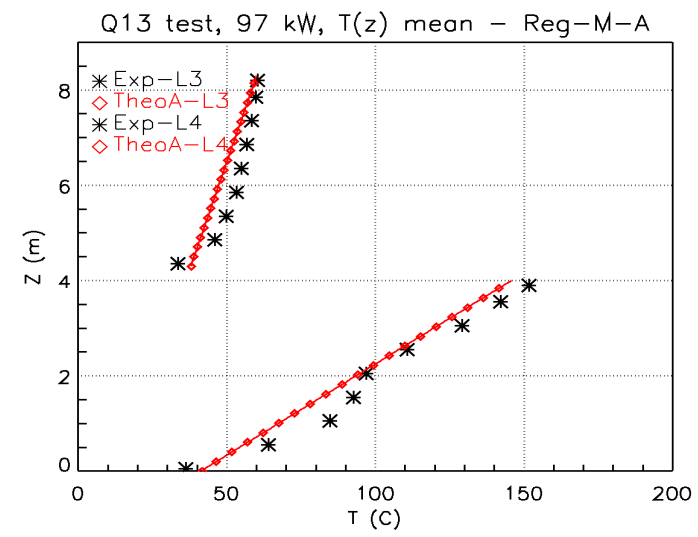

Fig. 5. Example of the results with the regression methods in the fire and adjacent rooms during the steady phase.

\section{Gas concentrations}

The time variation of oxygen $\left(\mathrm{O}_{2}\right)$ and carbon dioxide $\left(\mathrm{CO}_{2}\right)$ concentrations in both rooms show a rapid variation at the beginning of the fire test (either decrease of oxygen due to consumption or increase of $\mathrm{CO}_{2}$ due to production) followed by a steady phase during which all sampling points give constant level (Fig. 6). The duration of the initial unsteady phase differs according the location in the facility. The vent is the location where the steady condition is reached first followed by the concentration in the fire rooms and then the concentration in the adjacent room. The behavior is very similar between the two rooms. 

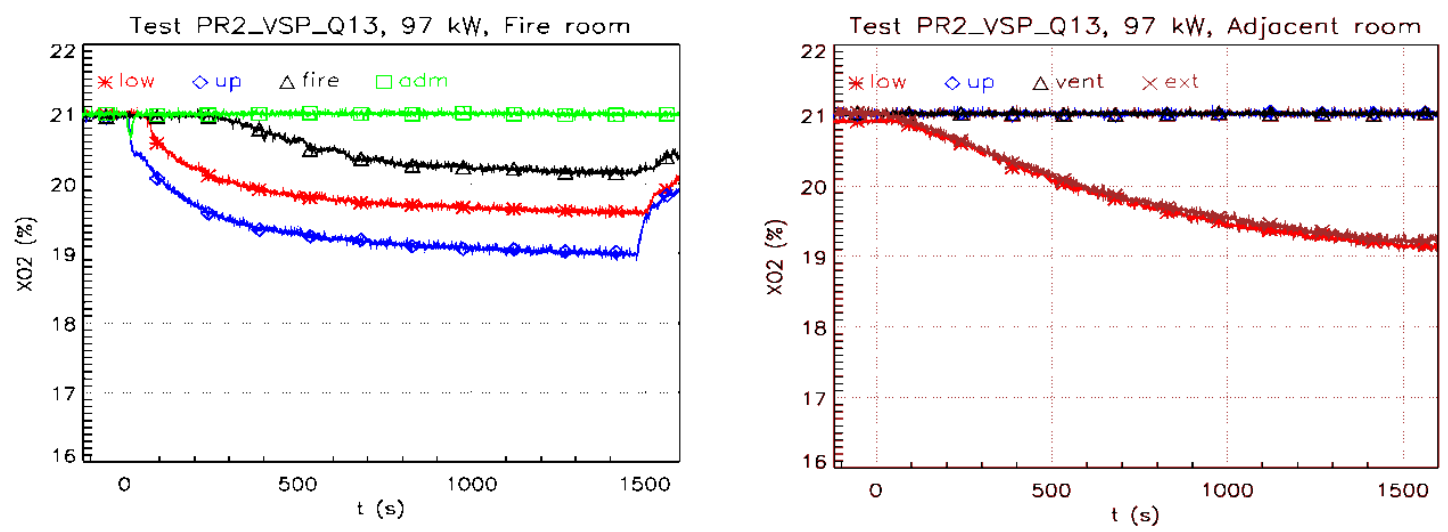

Fig. 6. Example of time variation of $\mathrm{O}_{2}$ and $\mathrm{CO}_{2}$ concentrations in the fire room $(N E)$ and adjacent room $(N E)$.

\section{EFFECT OF THE VENTILATION FLOW RATE}

The effect of the ventilation flow rate is discussed based on the fire behavior during the steady period (few minutes before extinction).

The change in the mean vertical temperature profile in the fire and adjacent rooms is presented in Fig. 7 for the four levels of renewal rate. The increase of the renewal rate modifies significantly the vertical temperature in the fire room. The change in the adjacent room is less pronounced.

In the fire room, the increase of the renewal rate decreases the overall temperature in the room but also modified the shape of the profile. For low level of ventilation flow rate $\left(T r=2.3 h^{-1}\right)$, the temperature profile shows a constant gradient. For the high level of ventilation flow rate $\left(\operatorname{Tr}=8.0 h^{-1}\right)$, the temperature profile is changing with the appearance of three zones, upper, intermediate and lower zones. The intermediate zone shows a constant temperature.

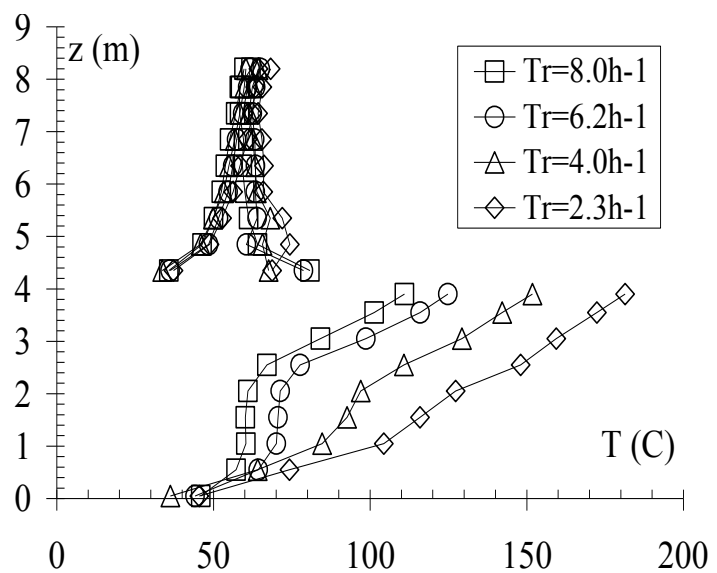

(a)

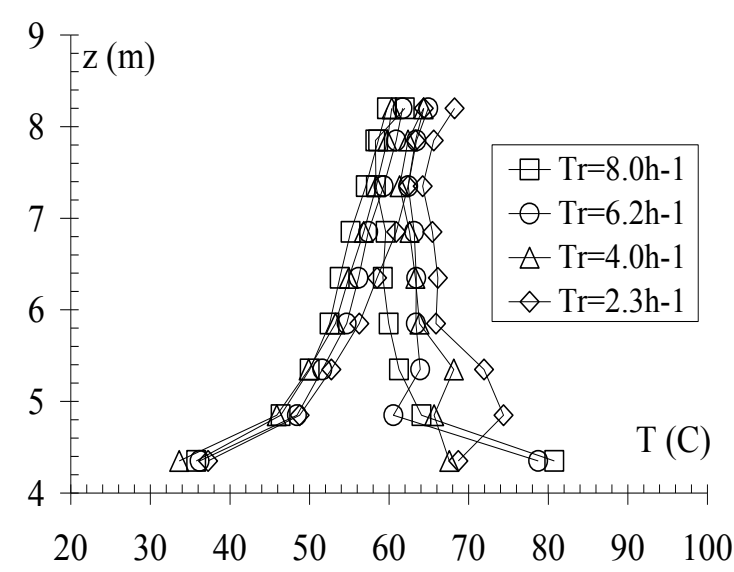

(b)

Fig. 7. Effect of the renewal rate on the vertical temperature profiles in the fire and adjacent rooms ((b) is a focus of the figure (a) for the profiles in the adjacent room).

In the adjacent room, two series of profiles are presented in Fig. 7 (b); one along the vertical vent axis and the other outside it. The series along the vent axis show a decrease in temperature as it is in the plume 
induced by the vent. The shape of the profile does not change with the ventilation flow rate. Only the overall temperature decreases due to a lower temperature of the buoyancy source (ie. the ceiling temperature in the fire room which decreases as the ventilation flow rate increases). Regarding the temperature profile of vent plume, the vertical temperature profile is similar in shape but changes slightly in amplitude due to a global cooling of the gas in the adjacent room. In the range of ventilation flow rates considered, the temperature in the lower part of the adjacent room is nearly not affected by the ventilation flow rate. The change of the temperature difference at the vent is mainly due to the change of the fire room temperature.

The effect of the ventilation flow rate on the mean upper and lower temperature computed from the regression method is presented in Fig. 8. Similar conclusions as those obtained with the temperature profile are found. There is nearly no lower layer in both rooms during the steady state; only the upper layer fills the rooms. The mean temperature in both rooms decreases with the increase of the renewal rate. The change in the fire room is much more significant than in the upper room.

The effect of the ventilation rate on the gas species concentrations is presented in Fig. 9. The variable considered for oxygen is the oxygen depletion formulated as $\Delta X_{O_{2}}(t)=X_{O_{2}}(t=0)-X_{O 2}(t)$. The increase of renewal rate contributes to dilute the gas species concentrations and therefore to decrease the oxygen depletion and the $\mathrm{CO}_{2}$ concentrations. The dilution is observed in both rooms.
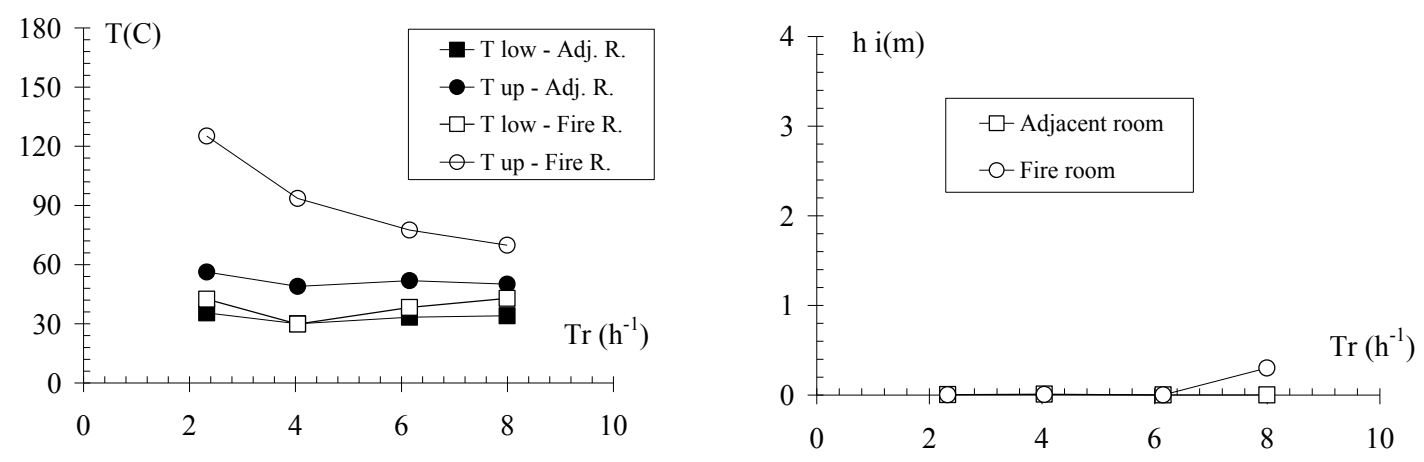

Fig. 8. Effect of ventilation flow rate on the upper and lower temperature and interface height in the fire and adjacent rooms.

The shape of the vertical profile differs between rooms. In the fire room there is a stratification of the concentration with higher oxygen depletion and $\mathrm{CO}_{2}$ concentration in the upper part of the room than in the lower part. In the adjacent room, no stratification is measured and the concentration seems to be constant in the whole room.
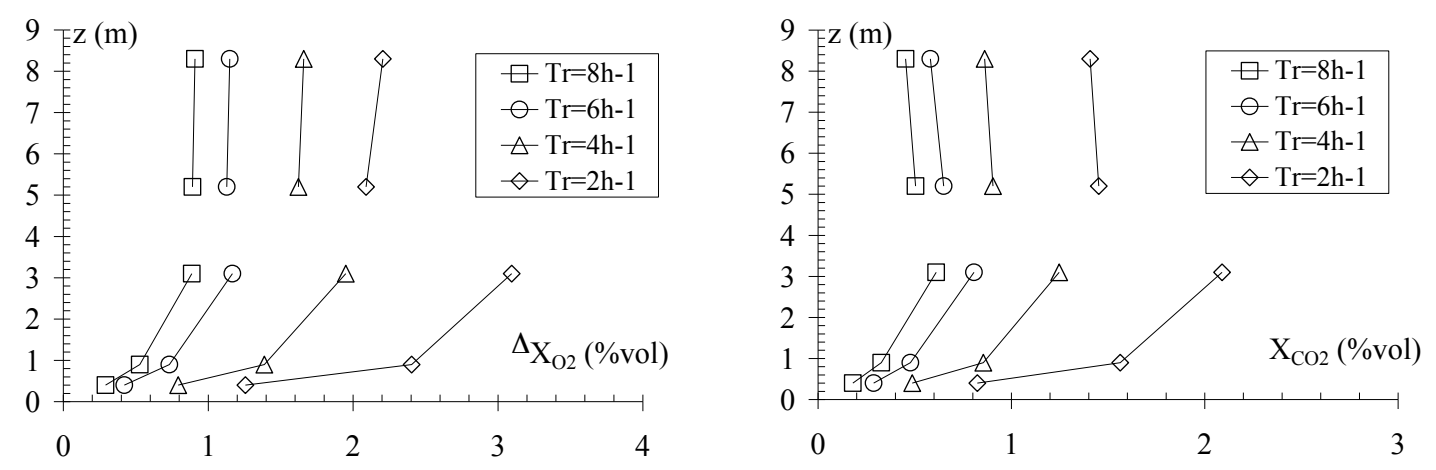

Fig. 9. Effect of ventilation flow rate on the $\mathrm{O}_{2}$ and $\mathrm{CO}_{2}$ concentration profiles in the fire and adjacent rooms. 


\section{VENT FLOW CALCULATION}

An indirect method is proposed to determine the vent flow rates (net, downward and upward) from the measurements of temperature and species concentrations in both room without considering any information measured directly at the vent. This indirect method has been largely used for small scale salt water modeling tests for which the direct measurement of the flow field at the vent was difficult to perform accurately. This method is applied here for large scale fire tests and is to be compared then to direct measurement performed on this same fire tests (Pretrel \& al. [9]).

\section{Indirect method technique}

The use of temperature and concentration in both rooms is used to determine the mass flow at the vent. For that, the mass conservations are written considering the schematic presented in Fig. 10.

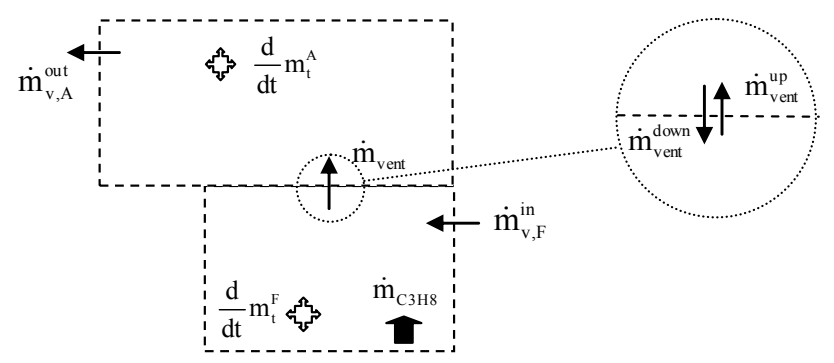

Fig. 10: Illustration of mass conservation.

The mass conservation for total mass, oxygen and carbon dioxide and for both rooms is specified as:

$$
\begin{aligned}
\frac{\mathrm{d}}{\mathrm{dt}}\left(\mathrm{m}_{\mathrm{t}}^{\mathrm{F}}\right) & =\dot{\mathrm{m}}_{\mathrm{v}, \mathrm{F}}^{\mathrm{in}}-\dot{\mathrm{m}}_{\mathrm{vent}}+\dot{\mathrm{m}}_{\mathrm{C} 3 \mathrm{H} 8} \\
\frac{\mathrm{d}}{\mathrm{dt}}\left(\mathrm{m}_{\mathrm{O} 2}^{\mathrm{F}}\right) & =\mathrm{Y}_{\mathrm{O} 2}^{\mathrm{v}, \mathrm{F}, \mathrm{in}} \dot{\mathrm{m}}_{\mathrm{v}, \mathrm{F}}^{\text {in }}-\dot{\mathrm{m}}_{\mathrm{O} 2, \mathrm{vent}}-\mathrm{r} \dot{\mathrm{m}}_{\mathrm{C} 3 \mathrm{H} 8} \quad \text { for the fire room } \\
\frac{\mathrm{d}}{\mathrm{dt}}\left(\mathrm{m}_{\mathrm{CO} 2}^{\mathrm{F}}\right) & =-\dot{\mathrm{m}}_{\mathrm{CO} 2, \mathrm{vent}}+3 \dot{\mathrm{m}}_{\mathrm{C} 3 \mathrm{H} 8}
\end{aligned}
$$

$$
\begin{array}{ll}
\frac{\mathrm{d}}{\mathrm{dt}}\left(\mathrm{m}_{\mathrm{t}}^{\mathrm{A}}\right)=-\dot{\mathrm{m}}_{\mathrm{v}, \mathrm{A}}^{\text {out }}+\dot{\mathrm{m}}_{\mathrm{vent}} & \\
\frac{\mathrm{d}}{\mathrm{dt}}\left(\mathrm{m}_{\mathrm{O} 2}^{\mathrm{A}}\right)=-\mathrm{Y}_{\mathrm{O} 2}^{\mathrm{v}, \mathrm{A}, \text { out }} \dot{\mathrm{m}}_{\mathrm{v}, \mathrm{A}}^{\text {out }}+\dot{\mathrm{m}}_{\mathrm{O} 2, \mathrm{v} \text { ent }} & \text { for the adjacent room } \\
\frac{\mathrm{d}}{\mathrm{dt}}\left(\mathrm{m}_{\mathrm{CO} 2}^{\mathrm{A}}\right)=-\mathrm{Y}_{\mathrm{CO} 2}^{\mathrm{v}, \mathrm{A}, \text { out }} \dot{\mathrm{m}}_{\mathrm{v}, \mathrm{A}}^{\text {out }}+\dot{\mathrm{m}}_{\mathrm{CO} 2, \mathrm{vent}} &
\end{array}
$$

In upper script ' $F$ ' and ' $A$ ' refer to fire room and adjacent room respectively, ' $i n$ ' and 'out' to the inlet and outlet lines of the ventilation network, ' $v$ ' to ventilation, ' $v e n t$ ' to the vent orifice and ' $C_{3} H_{8}$ ' to the fuel (propane in the present test). The variable ' $r$ ' is the stoichiometric ratio for the combustion of propane equal to $r=5 . M_{\mathrm{O}_{2}} / M_{\mathrm{C} 3 \mathrm{H} 8}=3.63$. All contributions except the vent flow rate can be computed from measurements and which therefore permits the determination of the vent flow rate.

The masses of oxygen and of carbon dioxide in the control volume are computed as follows:

$$
\mathrm{m}_{\mathrm{i}}=\frac{\mathrm{M}_{\mathrm{i}} \mathrm{P}}{\mathrm{R}} \mathrm{Sdz}\left(\mathrm{X}_{\mathrm{i}}^{\mathrm{L}} \sum_{\mathrm{j}=0}^{\mathrm{k}} \frac{1}{\mathrm{~T}_{\mathrm{j}}}+\mathrm{X}_{\mathrm{i}}^{\mathrm{U}} \sum_{\mathrm{j}=\mathrm{k}+1}^{\mathrm{n}} \frac{1}{\mathrm{~T}_{\mathrm{j}}}\right) \quad \text { with } \mathrm{i}=\mathrm{O}_{2} \text { and } \mathrm{CO}_{2}
$$

$\mathrm{S}$ is the area of the enclosure. The volume of gas is divided in slabs of elementary height (dz). Each slab corresponds to the location of a thermocouple. The pressure is the static pressure measured in the room. 
The mass of the species " $i$ " is determined from the two measurement points for gas concentration in the upper (U) and lower (L) part of the room, and gas temperature, from a vertical profile of $n=9$ thermocouples. The time variation of the mass is then computed using central derivatives and appropriate filtering treatment. The mass fluxes at the boundaries consist of inlet and outlet ventilation flow rates expressed as:

$$
\dot{\mathrm{m}}_{\mathrm{i}}^{\mathrm{V}, \text { in }}=\frac{\mathrm{M}_{\mathrm{i}} \mathrm{P}^{\text {in }}}{\mathrm{RT}_{\text {in }}} \mathrm{X}_{\mathrm{i}}^{\text {in }} \dot{\mathrm{v}}^{\text {in }} \quad \text { and } \quad \dot{\mathrm{m}}_{\mathrm{i}}^{\mathrm{V}, \text { out }}=\frac{\mathrm{M}_{\mathrm{i}} \mathrm{P}^{\text {out }}}{\mathrm{RT}_{\text {out }}} \mathrm{X}_{\mathrm{i}}^{\text {out }} \dot{\mathrm{v}}^{\text {out }} \quad \text { with } \mathrm{i}=\mathrm{O}_{2} \text { and } \mathrm{CO}_{2}
$$

The pressure, molar concentration and volumetric flow rates are measured along the inlet and exhaust branches of the ventilation network.

They are two expressions for the net flow at the vent whether the fire room or adjacent room are considered. Three relations are identified for the total mass, the mass of $\mathrm{O}_{2}$ and the mass of $\mathrm{CO}_{2}$ :

$$
\begin{aligned}
& \dot{\mathrm{m}}_{\mathrm{vent}}=\dot{\mathrm{m}}_{\mathrm{v}, \mathrm{F}}^{\text {in }}-\frac{\mathrm{d}}{\mathrm{dt}}\left(\mathrm{m}_{\mathrm{t}}^{\mathrm{F}}\right)+\dot{\mathrm{m}}_{\mathrm{C} 3 \mathrm{H} 8} \\
& \dot{\mathrm{m}}_{\mathrm{vent}}^{\mathrm{O} 2}=\mathrm{Y}_{\mathrm{O} 2}^{\mathrm{v}, \mathrm{F}, \mathrm{in}} \dot{\mathrm{m}}_{\mathrm{v}, \mathrm{F}}^{\text {in }}-\frac{\mathrm{d}}{\mathrm{dt}}\left(\mathrm{m}_{\mathrm{O} 2}^{\mathrm{F}}\right)-\mathrm{r} \dot{\mathrm{m}}_{\mathrm{C} 3 \mathrm{H} 8} \\
& \dot{\mathrm{m}}_{\mathrm{vent}}^{\mathrm{CO} 2}=-\frac{\mathrm{d}}{\mathrm{dt}}\left(\mathrm{m}_{\mathrm{CO} 2}^{\mathrm{F}}\right)+3 \dot{\mathrm{m}}_{\mathrm{C} 3 \mathrm{H} 8} \\
& \text { and } \\
& \begin{array}{c}
\dot{\mathrm{m}}_{\mathrm{vent}}=\frac{\mathrm{d}}{\mathrm{dt}}\left(\mathrm{m}_{\mathrm{t}}^{\mathrm{A}}\right)+\dot{\mathrm{m}}_{\mathrm{v}, \mathrm{A}}^{\text {out }} \\
\dot{\mathrm{m}}_{\mathrm{vent}}^{\mathrm{O} 2}=\frac{\mathrm{d}}{\mathrm{dt}}\left(\mathrm{m}_{\mathrm{O} 2}^{\mathrm{A}}\right)+\mathrm{Y}_{\mathrm{O} 2}^{\mathrm{v}, \mathrm{A}, \text { out }} \dot{\mathrm{m}}_{\mathrm{v}, \mathrm{A}}^{\text {out }} \\
\dot{\mathrm{m}}_{\mathrm{vent}}^{\mathrm{CO} 2}=\frac{\mathrm{d}}{\mathrm{dt}}\left(\mathrm{m}_{\mathrm{CO} 2}^{\mathrm{A}}\right)+\mathrm{Y}_{\mathrm{CO} 2}^{\mathrm{v}, \mathrm{A} \text {,out }} \dot{\mathrm{m}}_{\mathrm{v}, \mathrm{A}}^{\text {out }}
\end{array}
\end{aligned}
$$

In order to compute upward and downward flow, the net flow at the vent can be decomposed into two contributions. The following definitions are then considered:

$$
\begin{gathered}
\dot{\mathrm{m}}_{\text {vent }}=\dot{\mathrm{m}}_{\mathrm{vent}}^{\mathrm{U}}-\dot{\mathrm{m}}_{\mathrm{vent}}^{\mathrm{D}} \\
\dot{\mathrm{m}}_{\mathrm{vent}}^{\mathrm{O} 2}=\mathrm{Y}_{\mathrm{O} 2}^{\mathrm{U}} \dot{\mathrm{m}}_{\mathrm{vent}}^{\mathrm{U}}-\mathrm{Y}_{\mathrm{O} 2}^{\mathrm{D}} \dot{\mathrm{m}}_{\mathrm{vent}}^{\mathrm{D}} \\
\dot{\mathrm{m}}_{\mathrm{vent}}^{\mathrm{C} 2}=\mathrm{Y}_{\mathrm{CO} 2}^{\mathrm{U}} \dot{\mathrm{m}}_{\mathrm{vent}}^{\mathrm{U}}-\mathrm{Y}_{\mathrm{CO} 2}^{\mathrm{D}} \dot{\mathrm{m}}_{\mathrm{vent}}^{\mathrm{D}}
\end{gathered}
$$

The mass fractions of species $Y_{\mathrm{O} 2}{ }^{U}, \mathrm{Y}_{\mathrm{O} 2}{ }^{\mathrm{D}}, \mathrm{Y}_{\mathrm{CO} 2}{ }^{\mathrm{U}}$ and $\mathrm{Y}_{\mathrm{CO} 2}{ }^{\mathrm{D}}$ are the average mass fraction in $\mathrm{O}_{2}$ or $\mathrm{CO}_{2}$ of the flow going upward or downward. From relations (6), the upward and downward flow rates are can be expressed with oxygen or carbon dioxide concentrations:

$$
\begin{aligned}
& \dot{\mathrm{m}}_{\mathrm{vent}}^{\mathrm{U}}=\frac{\dot{\mathrm{m}}_{\mathrm{vent}}^{\mathrm{CO} 2}-\mathrm{Y}_{\mathrm{CO} 2}^{\mathrm{D}} \dot{\mathrm{m}}_{\mathrm{vent}}}{\mathrm{Y}_{\mathrm{CO} 2}^{\mathrm{U}}-\mathrm{Y}_{\mathrm{CO} 2}^{\mathrm{D}}}=\frac{\dot{\mathrm{m}}_{\mathrm{vent}}^{\mathrm{O} 2}-\mathrm{Y}_{\mathrm{O} 2}^{\mathrm{D}} \dot{\mathrm{m}}_{\mathrm{vent}}}{\mathrm{Y}_{\mathrm{O} 2}^{\mathrm{U}}-\mathrm{Y}_{\mathrm{O} 2}^{\mathrm{D}}} \\
& \dot{\mathrm{m}}_{\mathrm{vent}}^{\mathrm{D}}=\frac{\dot{\mathrm{m}}_{\mathrm{vent}}^{\mathrm{CO}}-\mathrm{Y}_{\mathrm{CO} 2}^{\mathrm{U}} \dot{\mathrm{m}}_{\mathrm{vent}}}{\mathrm{Y}_{\mathrm{CO} 2}^{\mathrm{U}}-\mathrm{Y}_{\mathrm{CO} 2}^{\mathrm{D}}}=\frac{\dot{\mathrm{m}}_{\mathrm{vent}}^{\mathrm{O}}-\mathrm{Y}_{\mathrm{O} 2}^{\mathrm{U}} \dot{\mathrm{m}}_{\mathrm{vent}}}{\mathrm{Y}_{\mathrm{O} 2}^{\mathrm{U}}-\mathrm{Y}_{\mathrm{O} 2}^{\mathrm{D}}}
\end{aligned}
$$

The mass fractions of species $Y_{\mathrm{O} 2}{ }^{U}, Y_{\mathrm{O} 2}{ }^{D}, Y_{\mathrm{CO} 2}{ }^{U}$ and $Y_{\mathrm{CO} 2}{ }^{D}$ have not been measured directly within the vent cross section and therefore theirs magnitude are estimated from other measurement points. The specie mass fractions of the upward vent flow are supposed to be close to those in the upper part of the fire room, $Y_{i}^{U} \sim Y_{i, L 3}{ }^{H A U T}$ (' $i$ ' stands for $\mathrm{O}_{2}$ or $\mathrm{CO}_{2}$, see nomenclature and Fig. 2) and the species mass fractions of the vent downward flow close to those in the lower part of the adjacent room, $Y_{i}^{D} \sim Y_{i, L 4}{ }^{B A S}$. The results are indicated in Table 2 which mentioned all the contributions defined in the mass balance equation.

\section{Discussion}

In the fire room, the total net mass flow rate at the vent is mainly equal to the inlet flow rate from the ventilation. Indeed, the contribution of the mass flow rate of fuel is weak (about 1\%). Regarding oxygen, 
the net flow rate of oxygen at the vent correspond to the flow rate brought by the ventilation minus the contribution consumed by the combustion process which represents between $16 \%$ to $5 \%$ corresponding to renewal rates of $2.6 \mathrm{~h}^{-1}$ and $8.0 \mathrm{~h}^{-1}$ respectively. Regarding carbon dioxide specie, the net flow rate at the vent is the only result of the production due to the combustion process. For the three quantities (total mass, $\mathrm{O}_{2}$ and $\mathrm{CO}_{2}$ ) the contribution of the unsteady term is nearly negligible which confirms the condition of quasi-steady regime.

In the adjacent room, the mass flow rates at the vent for total mass, oxygen and carbon dioxide are almost those measured at the exhaust line of the ventilation. There are no consumed nor production of species in this room and because the quasi-steady regime is considered, the unsteady terms are also very weak contributions.

From the net flow rate at the vent (relations (5), two values can be computed whether the fire room (FR) or the adjacent room (AR) is considered for the mass balance. Their variation versus the renewal rate is presented in Fig. 11 for the total mass, the mass of oxygen and the mass of carbon dioxide. The two formulations (FR and AR) give nearly the same values which give us confidence in the quality of the measurements in the two rooms. A comparison is made on Fig. 12 with direct measurements of the net flow rate. These measurements have been obtained from spatial integration of velocity field in the cross section of the vent measured with 13 velocity probes. The integration is performed over the physical area of the vent (Pretrel \& al. [9]). There is a satisfactory accordance between the two techniques. The indirect method from data measured away from the vent can give a good estimate of the net flow rate at the vent.

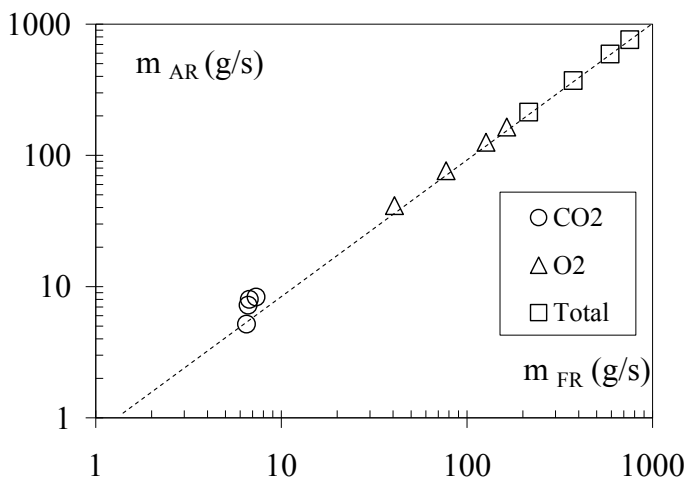

Fig. 11. Comparison of the net flow rate (total, $\mathrm{O}_{2}$ and $\mathrm{CO}_{2}$ ) from the mass balance in the fire room

(FR) and in the adjacent room (AR).

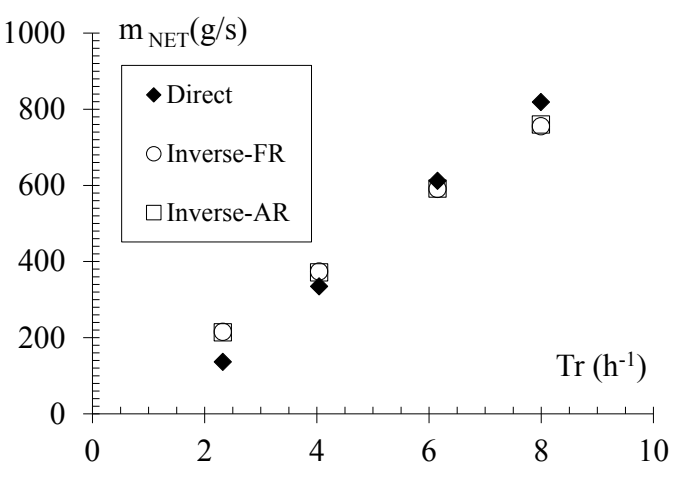

Fig. 12. Net vent flow rate versus the renewal rate.

From the calculation of the net flow rate at the vent, the calculation of upward and downward flow can be performed with relations (7). For each contribution (upward or downward), there are two possible relations whether the oxygen or carbon dioxide are considered. In addition, in each relation, the net flow rates are required $\left(m_{\text {vent }}, m_{\text {vent }}{ }^{\mathrm{O}}\right.$ or $\left.m_{\text {vent }}, m_{\text {vent }}{ }^{\mathrm{CO} 2}\right)$ and can be obtained from two different ways either from the mass balance in the fire room (FR) either from mass balance in the adjacent rooms (AR). Therefore four possible computations are performed for the upward and downward flows (named ' $O 2_{-} F R^{\prime}$ ', $O 2_{-} A R$ ', 'CO2_FR' and ' $C O 2 \_A R$ ') and indicated in Table 2. These data are presented versus the renewal rate in Fig. 13 and Fig. 14 (for large $T r$, the values are too large to be shown in the abscissa and ordinate scales of the figure). They are also compared to direct measurement obtained from spatial integration of velocity field (Pretrel \& al. [9]). 
Table 2: Data of the vent flow calculation

\begin{tabular}{|c|c|c|c|c|c|c|}
\hline & \multicolumn{2}{|l|}{ TEST } & \multirow{2}{*}{$\begin{array}{c}\text { Q17 } \\
2.3\end{array}$} & \multirow{2}{*}{$\begin{array}{l}\text { Q13 } \\
4.0\end{array}$} & \multirow{2}{*}{$\begin{array}{l}\text { Q16 } \\
6.2\end{array}$} & \multirow{2}{*}{$\begin{array}{c}\text { Q12 } \\
8.0\end{array}$} \\
\hline & $\mathrm{Tr}$ & $\overline{\left(\mathrm{C}^{-1}\right)}$ & & & & \\
\hline \multirow{12}{*}{ 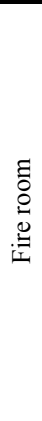 } & \multirow{4}{*}{$\begin{array}{l}\text { ddt_mt_L3 } \\
\text { V_in } \\
\text { MLR } \\
\text { Vent net } \\
\end{array}$} & $\mathrm{g} / \mathrm{s}$ & 1 & 3 & 2 & -1 \\
\hline & & $\mathrm{g} / \mathrm{s}$ & 212 & 368 & 586 & 754 \\
\hline & & $\mathrm{g} / \mathrm{s}$ & 2 & 2 & 2 & 2 \\
\hline & & $\mathrm{g} / \mathrm{s}$ & 215 & 374 & 591 & 755 \\
\hline & \multirow{4}{*}{$\begin{array}{l}\text { ddt_mt_L3 O2 } \\
\text { V_in L3 O2 } \\
\text { MLR*r } \\
\text { Vent O2 net }\end{array}$} & $\bar{g} / \mathrm{s}$ & 1 & 1 & 1 & -1 \\
\hline & & $\mathrm{g} / \mathrm{s}$ & 48 & 85 & 134 & 173 \\
\hline & & $\mathrm{g} / \mathrm{s}$ & 8 & 8 & 8 & 8 \\
\hline & & $\mathrm{g} / \mathrm{s}$ & 41 & 77 & 127 & 164 \\
\hline & \multirow{4}{*}{$\begin{array}{l}\text { ddt_L3 CO2 } \\
\text { V_in L3 CO2 } \\
\text { MLR*3 } \\
\text { Vent CO2 net }\end{array}$} & $\bar{g} / \mathrm{g}$ & -0.2 & -0.1 & 0.0 & 0.6 \\
\hline & & $\mathrm{g} / \mathrm{s}$ & 0.0 & 0.0 & 0.0 & 0.0 \\
\hline & & $\mathrm{g} / \mathrm{s}$ & 6.7 & 6.7 & 6.7 & 6.7 \\
\hline & & $\mathrm{g} / \mathrm{s}$ & 6.5 & 6.6 & 6.7 & 7.3 \\
\hline \multirow{9}{*}{ 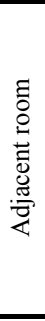 } & \multirow{3}{*}{\begin{tabular}{|l}
$d d t \_m t \_L 4$ \\
V_out 14 \\
Vent net \\
\end{tabular}} & $\mathrm{g} / \mathrm{s}$ & 3 & 4 & 2 & 6 \\
\hline & & $\mathrm{g} / \mathrm{s}$ & 217 & 375 & 593 & 766 \\
\hline & & $\mathrm{g} / \mathrm{s}$ & 214 & 371 & 591 & 760 \\
\hline & \multirow{3}{*}{$\begin{array}{l}d d t \_L 4 \text { O2 } \\
\text { V_out L4 O2 } \\
\text { Vent O2 net }\end{array}$} & $\mathrm{g} / \mathrm{s}$ & 2 & 1 & 1 & 1 \\
\hline & & $\mathrm{g} / \mathrm{s}$ & 43 & 78 & 127 & 166 \\
\hline & & $\mathrm{g} / \mathrm{s}$ & 41 & 76 & 126 & 165 \\
\hline & \multirow{3}{*}{\begin{tabular}{|l|}
$d d t \_L 4$ CO2 \\
V_out L4 CO2 \\
Vent CO2 net \\
\end{tabular}} & $\mathrm{g} / \mathrm{s}$ & -0.7 & -0.4 & -0.1 & 0.0 \\
\hline & & $\mathrm{g} / \mathrm{s}$ & 4.5 & 6.8 & 7.9 & 8.3 \\
\hline & & $\mathrm{g} / \mathrm{s}$ & 5.2 & 7.2 & 8.0 & 8.3 \\
\hline \multirow{12}{*}{ 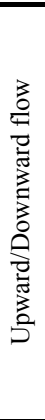 } & $\mathrm{X} \mathrm{O} 2-\mathrm{F}$ & $\%$ & 17.075 & 18.558 & 19.382 & 19.725 \\
\hline & $\mathrm{XCO} 2-\mathrm{F}$ & $\%$ & 1.98 & 1.22 & 0.77 & 0.59 \\
\hline & X O2-A & $\%$ & 18.142 & 18.882 & 19.406 & 19.710 \\
\hline & $\mathrm{XCO} 2-\mathrm{A}$ & $\%$ & 1.28 & 1.04 & 0.75 & 0.61 \\
\hline & $\mathrm{UP}(\mathrm{O} 2, \mathrm{FR})$ & $\mathrm{g} / \mathrm{s}$ & 206 & 168 & -432 & -4861 \\
\hline & UP (O2,AR) & $\mathrm{g} / \mathrm{s}$ & 114 & 272 & 3970 & 9695 \\
\hline & $\mathrm{UP}(\mathrm{CO} 2, \mathrm{FR})$ & $\mathrm{g} / \mathrm{s}$ & 215 & 264 & 629 & -938 \\
\hline & $\mathrm{UP}(\mathrm{CO} 2, \mathrm{AR})$ & $\mathrm{g} / \mathrm{s}$ & 95 & 477 & -502 & -13620 \\
\hline & $\bar{D}(\mathrm{D}(\mathrm{O} 2, \mathrm{FR})$ & $\bar{g} / \mathrm{g} / \mathrm{s}$ & 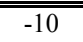 & 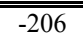 & -1022 & -5619 \\
\hline & $\mathrm{D}(\mathrm{O} 2, \mathrm{AR})$ & $\mathrm{g} / \mathrm{s}$ & -101 & -100 & 3379 & 8941 \\
\hline & $\mathrm{D}(\mathrm{CO} 2, \mathrm{FR})$ & $\mathrm{g} / \mathrm{s}$ & -1 & -110 & 38 & -1696 \\
\hline & $\mathrm{D}(\mathrm{CO} 2, \mathrm{AR})$ & $\mathrm{g} / \mathrm{s}$ & -120 & 105 & -1092 & -14373 \\
\hline
\end{tabular}

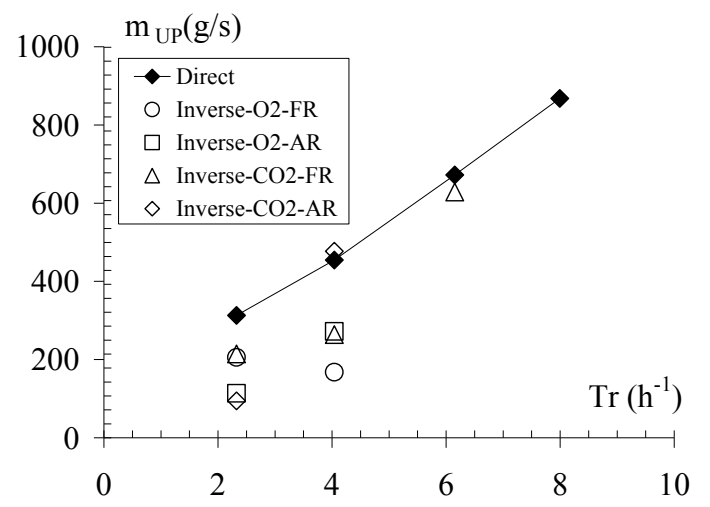

Fig. 13. Upward vent flow rate versus the renewal rate.

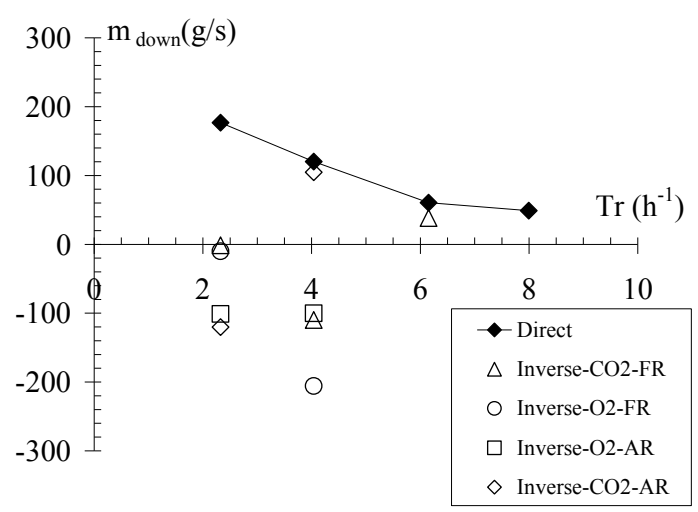

Fig. 14. Downward vent flow rate versus the renewal rate. 
For a given renewal rate, the four formulations lead to large scattering for both upward and downward flows. This scattering increases with the renewal rate. For the largest ventilation flow rates $\left(T r=6.2 \mathrm{~h}^{-1}\right.$ and $\left.T r=8.0 \mathrm{~h}^{-1}\right)$, the computations give non physical values. One reason is the low magnitude of the differences $\left(Y_{\mathrm{O}_{2}}{ }^{U}-Y_{\mathrm{O} 2}{ }^{D}\right)$ and $\left(Y_{\mathrm{CO} 2}{ }^{U}-Y_{\mathrm{CO} 2}{ }^{D}\right)$ (that appear at the denominator of the relations (7)) which decrease with the renewal rate. These low amplitudes are due to the fact that there is not enough consumption of $\mathrm{O}_{2}$ or production of $\mathrm{CO}_{2}$ within the fire room.

In addition, the computation of the downward flow gives negative value for most of the calculations. The reason for that is the fact that the numerators of the relations (7) $\left(Y_{O 2}{ }^{U} \cdot m_{n e t}-m_{n e t}{ }^{O 2}\right)$ are negative although it should not. Considering that the net mass flow rates have acceptable accuracy (see analysis of Fig. 11), the possible explanation for the negative value is attributed to the values of the species mass fractions at the vent $\left(Y_{\mathrm{O} 2}{ }^{U}\right.$ or $\left.Y_{\mathrm{CO}_{2}}{ }^{U}\right)$. The accuracy for these quantities is not large enough for the present data set and the use of the indirect method for the determination of the downward flow is not possible. A second explanation is that the downward flow could be nil and the vent flow only one directional. Although the direct measurements show an effective downward flow, it is possible that this downward motion (that exists effectively at the vent cross section) is rapidly redirected upstream and therefore has no impact on the concentration species in the lower room. From the global point of view of mean species concentration in the rooms, there is no downward flow affecting the gas concentrations in the lower room although locally a downward contribution can be identify at the vent cross section. This is the reason why, with relations obtained from global mass conservation, no physical value of the downward flow is obtained.

This analysis suggests that two situations for the downward flow induced by the fire can be identified (see Fig. 15). A first one depicts a situation where the downward flow is weak, does not flows deeply in the fire room and therefore has nearly no impact on the concentration of the lower room smoke layer. A second situation concerns a configuration for which the downward flow is larger, moves deeper in the fire room and therefore modifies the concentration of the smoke layer. In that case, a global formulation based on mass conservation can detect this flow. The present set of fire tests concerns the first scenario.
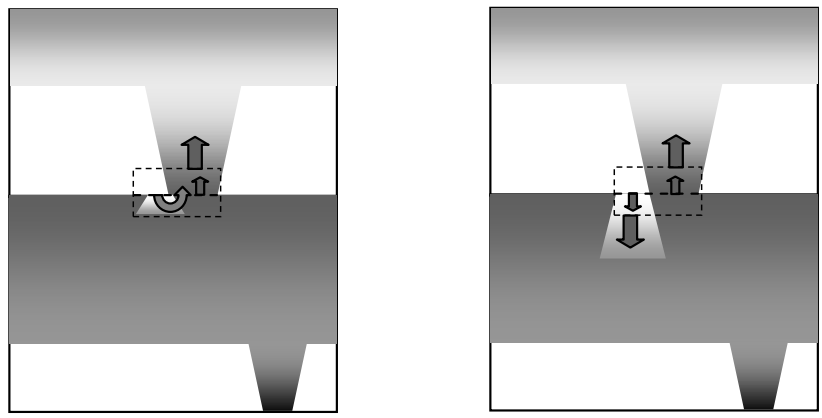

Fig. 15. Illustration of two configurations with different effect of the downward flow

\section{CONCLUSIONS}

The present contribution investigates smoke flow through a vent for confined and mechanically-ventilated fire scenarios. Based on large scale fire tests, it discusses the effect of vent flow on smoke flow from both side of the vent. The tests concern a $97 \mathrm{~kW}$ propane fire in a $120 \mathrm{~m}^{3}$ enclosure connected to an adjacent superposed $170 \mathrm{~m}^{3}$ enclosure, both mechanically ventilated. The configuration of ventilation is particular with an inlet in the fire room and an exhaust line in the upper adjacent room. The renewal rate is typical to operating conditions in nuclear installations (from 2.3 to $8.0 \mathrm{~h}^{-1}$ ). The vent is a rectangular orifice of $1.06 \mathrm{~m}^{2}$.

The vent flow induces specific smoke stratification in the enclosures. The vertical temperature profiles in both rooms are typical to fire enclosure scenario. The profiles do not show two layers with constant homogeneous temperature but one layer with significant vertical temperature gradient. The vertical distribution of oxygen and carbon dioxide concentrations shows similar profiles.

The effect of the ventilation flow rate (or renewal rate) on the smoke distribution is investigated. The increase of the renewal rate cools down the smoke temperature and dilutes the smoke concentration. The 
influence is more pronounced in the fire room with a significant change in the shape of the temperature stratification.

The smoke temperature and smoke concentrations are considered to compute the vent flow rate through the horizontal vent. Two indirect methods are considered based on mass balance conservations of species $\left(\mathrm{CO}_{2}\right.$ and $\mathrm{O}_{2}$ ) in the two rooms. The two methods allow the computation of the net flow rate, the upward and downward flow rates. These results are then compared with direct measurements obtained from spatial integration of velocity filed in the cross section of the vent (Pretrel \& al. [9]). There is a good accordance between the two methods for the net mass flow rate at the vent. Nevertheless, the downward and upward mass flow does not give as good accordance with the direct measurement. These results are explained by the fact that the regime of vent flow for the present fire tests does not permit to determine the bidirectional flow with the indirect method. This analysis indicates that both methods (direct and indirect) are complementary methods able to quantify the vent flow rates. The indirect method brings complementary information, especially about the influence of the vent flows on temperature and species concentrations in case of two rooms separated by a vent-type orifice.

Nevertheless, the flow field at the vent may be the results of local behavior that can be considered with global mass balance as those used for the indirect method. Future works are underway to investigate the vent with CFD fire code in order to improve the flow understanding.

\section{REFERENCES}

[1] Brown, W.G., (1962) Natural convection through rectangular openings in partitions, Part 2 Horizontal partitions, International journal of heat and Mass transfer, 5 (1962), 869-881, http://dx.doi.org/10.1016/0017-9310(62)90185-0.

[2] Epstein, M., Kenton, M.A., (1989) Combined Natural Convection and Forced Flow Through Small Openings in a Horizontal Partition With Special Reference to Flows in Multi-compartment Enclosures, J. Heat Transfer 111(4), 980-987, http://dx.doi.org/10.1115/1.3250814.

[3] Heskestad, G., Spaulding, R.D., "Inflow of Air Required at Wall and Ceiling Apertures to Prevent Escape of Fire Smoke", Fire Safety Science, - Proceedings of the 3rd international Symposium, International Association for Fire Safety Science, 1991, pp. 919-928

[4] Tan, Q., Jaluria, Y., (2001) Mass flow through a horizontal vent in an enclosure due to pressure and density differences, International Journal of Heat and Mass Transfer, 44, pp. 1543-1553, http://dx.doi.org/10.1016/S0017-9310(00)00198-8.

[5] Cooper, L.Y., "Calculation of the Flow through a Horizontal Ceiling/Floor Vent", National Institute of Standards and Technology Report NISTIR 89-4052, Gaithersburg, MD, 1989; p30.

[6] Cooper, L.Y., (1996) Calculating Combined Buoyancy- and Pressure-driven Flow Through a Shallow, Horizontal, Circular Vent: Application to a Problem of Steady Burning in a Ceilingvented Enclosure, Fire Safety Journal, 127, pp.23-35, http://dx.doi.org/10.1016/S03797112(96)00041-0

[7] Emmons, H. W., Tanaka, T., "Vent Flows", The SFPE Handbook of Fire protection Engineering, $\left(4^{\text {th }}\right.$ ed) DiNenno P.J. (ed.), National Fire Protection Association, Quincy, MA 02269, 2008, p. 237/2-53.

[8] Hagglund, B., Werling, P. and Bengtson, S., “An Experimental Study Of The Smoke Spread In A Two-Plane Compartment", Proceedings of the third Asia-Oceania symposium on fire science \& technology, International Association for Fire Safety Science, 1988, pp 451-470.

[9] Pretrel, H., Liberati, J., Audouin, L., Vauquelin, O., "Smoke flow through a horizontal vent separating two mechanically ventilated rooms from large scale fire tests", Proceedings of the 13 International Interflam Conference, Interscience Communications 2013, pp 241-252.

[10] Audouin, L., Tourniaire, B., "New estimation of the thermal interface height in forced-ventilation enclosure fires", Fire Safety Science, - Proceedings of the 6th international Symposium, International Association for Fire Safety Science, 2000, pp. 555-566. 